\section{How to reduce the toll of road traffic accidents}

Each year in the UK some 3400 people are killed on the roads, of whom 218 are children. ${ }^{1}$ A further 37000 are seriously injured and 272500 slightly injured. The average person in a developed country has a one in hundred lifetime risk of being killed in a road traffic accident (RTA) and a one in three lifetime risk of being injured. ${ }^{2}$

RTAs affect more than just car drivers and passengers: the year 2001 saw 823 pedestrians killed in RTAs and 40563 injured, ${ }^{3}$ and the figures for pedal cyclists were 138 and 19094 . Of motorcyclists, 581 died and 28768 were injured.

How might this modern epidemic be mitigated? The figures for road crash deaths could drop by as much as $20 \%$ if vehicles complied with the recommendations of the European Enhanced Vehicle Safety Committee (EEVC). ${ }^{1}$ This would require changes in design to lessen injury to pedestrians. Most pedestrians are hit by the front of the car, so the most common sites of injury are the head and lower limbs. ${ }^{5}$ The bumper contacts the lower limbs, and the body then wraps itself around the car with the head finally hitting the lower windscreen or bonnet. ${ }^{5}$

One proposal is to set bumpers lower, so that the femur and tibia rotate together on impact, avoiding the lateral stress on the knee that can result from femoral rotation alone. Bumpers should also contain an extra layer of energy absorbing material to reduce the impact force. ${ }^{5}$ Bonnets should be more than $10 \mathrm{~cm}$ clear of underlying structures to ensure flexibility if struck by a head. Other ways to provide clearance are airbags in the region of the lower windscreen and pop-up bonnets. ${ }^{5}$ There is a voluntary agreement among European car manufacturers that all new cars after 2010 will comply with EEVC requirements.

Until recently efforts to improve safety for pedestrians have centered on two approaches - isolation from vehicles by use of footbridges and crossings; and public education, particularly of children, ${ }^{5}$ to encourage responsible behaviour. There is only modest evidence in favour of the educational approach. ${ }^{6,7} \mathrm{~A}$ new development is the advent of 'home zones', with measures to restrict the volume and speed of traffic in the interests of pedestrians and cyclists. ${ }^{8}$

Protection for car passengers has been much more widely researched although car occupants are less vulnerable in RTAs than pedestrians or most other road users. The use of seat belts is thought to reduce the risk of death by up to $65 \%$ (68\% if a car is fitted with an air bag). ${ }^{9}$ Children, however, are poorly served. RTAs are a leading cause of death for children aged between four and fourteen in the UK but as yet there are no seat belts specifically designed for their use. ${ }^{10}$ Current seat belts are designed to restrain adults just below their centre of gravity, at the pelvis. ${ }^{10} \mathrm{~A}$ child's pelvis is unable to provide an anchor point for restraint until about ten years of age, ${ }^{10}$ and the belt can therefore injure the abdomen and mid-lumbar region (lap belt syndrome). ${ }^{10,11} \mathrm{~A}$ torso strap may also increase the risk of cervical spine injuries to the child. ${ }^{10}$ Nevertheless, seat belts still confer a 2-10 times advantage in the event of a crash, and it is disturbing that some $40 \%$ of older children do not wear them when travelling in motor vehicles. ${ }^{10-12}$

In about one-third of RTAs, inappropriate speed is the major cause. Collisions at $20 \mathrm{mph}$ result in a $5 \%$ risk of death, whilst those at $85 \mathrm{mph}$ result in an $85 \%$ risk of death. According to a study by the Department of Transport in 2001, the introduction of speed cameras reduced casualties in the immediate vicinity by $47 \%$ and in surrounding areas by $18 \% .{ }^{13}$ To combat speed many local authorities are now introducing traffic calming measures including $20 \mathrm{mph}$ zones outside schools and in town centres, speed humps and speed-activated signs at hazards. ${ }^{14,15}$

Another large threat to road safety is alcohol. Of 1086 motor vehicle driver and motorcycle riders who died in RTAs, $19 \%$ were over the legal limit of $80 \mathrm{mg} / \mathrm{dL}$. The highest proportion of these drivers were aged 30-39 years. ${ }^{15}$ Use of mobile phones while driving seems to be increasing rather than decreasing, especially by drivers on fast rural roads. ${ }^{16}$ On motorways sleepiness is a particular hazard, believed to account for $15-20 \%$ of accidents. ${ }^{17,18}$ To combat sleepiness the recommended approaches are to stop and take a short nap (less than 15 minutes), ${ }^{17,19}$ to drink caffeine (around $200 \mathrm{mg}$ or two cups), ${ }^{17,20}$ or to do both since caffeine takes 20-30 minutes to be absorbed and act.

What about medical care when an accident happens? Since transport to hospital usually takes $30-45$ minutes, the 'golden hour' in which $48 \%$ of deaths occur is spent mainly in the prehospital environment. ${ }^{21,22}$ In the UK about 50\% of deaths occur at the site of an accident or during transport. Those who argue for better emergency management say that $40 \%$ of deaths due to RTAs could be 
prevented if the victims received appropriate treatment either before arriving at hospital or subsequently in well coordinated departments. ${ }^{2,21}$

By 2020 RTAs are expected to have moved from ninth to third place in the world ranking of burden of disease. ${ }^{1}$ Yet this modern epidemic is strangely neglected. Much could already be done, but is not being done, to reduce the toll of death and disability.

\section{Rodger Charlton}

\section{Gary Smith ${ }^{1}$}

Warwick Medical School, University of Warwick, Coventry CV4 7AL;

${ }^{1}$ University of Birmingham Medical School, Birmingham, UK

E-mail: rodger.charlton@warwick.ac.uk

\section{REFERENCES}

1 Roberts I, Mohan D, Abbasi K. War on the roads. BMJ 2002; 324:1107-8

2 Haegi M. A new deal for road crash victims. BMJ 2002;324:1110

3 Department for Transport. Road casualties: Great Britain — main results (Provisional), 2001. Statistics Bulletin (02)20 [http://www. transtat.dft. gov.uk/tables/2002/rcas/pdf/rcas01.pdf]

4 DETR. Road Accidents Great Britain 1998 [http://www.pacts.org. uk/ statistics_uk.htm]

5 Crandall JR, Bhalla KS, Madeley NJ. Designing road vehicles for pedestrian protection. BMJ 2002;324:1145-8

6 Duperrex O, Bunn F, Roberts I. Safety education of pedestrians for injury prevention: a systematic review of randomized controlled trials. BMJ 2002;324:1129-31

7 University of York: NHS Centre for Reviews and Dissemination University of Leeds: Nuffield Institute for Health. Preventing unintentional injuries in children and young adolescents. Effective Health Care Bulletin 1996;2(5)
8 Department for Transport. Local Transport Settlement Factsheet: Road Safety, $2000 \quad$ [http://www.local-transort.dft.gov.uk/trps/ themesheets/roadsafety/]

9 Cummings P, McKnight B, Rivara FP, Grossman DC. Association of driver airbags with driver fatality: a matched cohort study. BMJ 2002;324:1119-22

10 Halman S, Chipman M, Parkin PC, Wright JG. Are seat belt restraints as effective in school age children as in adults? A prospective crash study. BMJ 2002;324:1123-5

11 Mickalide AD, DiCapua K, Paul H. Ensuring the safety of school age passengers. BMJ 2002;324:1108-9

12 Transport Research Laboratory. Restraint use by care occupants, 2000-2002. Crowthorne: Transport Research Laboratory, 2002

13 Department for Transport. Cost Recovery System for Traffic Safety Cameras: First Year Report - executive summary. [http://www.roads.dft.gov.uk/ roadsafety/costrec/]

14 Department for Transport. Tomorrow's Roads: Safer for Everyone [http:// www.roads.dft.gov.uk/roadsafety/strategy/tomorrow/index.htm]

15 Transport Research Laboratory. Blood Alcohol Levels in Road Accident Fatalities for 2000 in Great Britain. Crowthorne: Transport Research Laboratory, 2002

16 Transport Research Laboratory. Mobile Phone Use by Car Drivers, 2000 2002. Crowthorne: Transport Research Laboratory, 2002

17 Department for Transport. Driver sleepiness: overview of findings from phase 3 of DETR Research Programme. Road Safety Res Rep, No. 21, 2001 [http://www.roads.dft.gov.uk/roadsafety/research21/ index.htm]

18 Horne JA, Reyner LA. Sleep related vehicle accidents. BMJ 1995; 310:565-7

19 Reyner LA, Horne JA. Suppression of sleepiness in drivers: combination of caffeine with a short nap. Psychophysiology 1997;34:721-5

20 Horne JA, Reyner LA. Counteracting driver sleepiness: effects of napping, caffeine and placebo. Psychophysiology 1996;33:306-9

21 Coats TJ, Davies G. Prehospital care for road traffic casualties. BMJ 2002;324:1135-8

22 Transport Research Laboratory. Time Interval between Road Accident and Death, 1997. Crowthorne: Transport Research Laboratory, 2000 